\title{
PENGEMBANGAN PERANGKAT LUNAK MONITORING WELLIES DENGAN METODE WATERFALL MODEL
}

\author{
Baibul Tujni ${ }^{1}$, Hutrianto ${ }^{2}$ \\ Dosen Universitas Bina Darma ${ }^{1,2}$ \\ Jalan Jenderal Ahmad Yani No.3 Palembang \\ Sur-el : baibul.tujni@binadarma.ac.id 1, hutrianto@binadarma.ac.id ${ }^{2}$
}

\begin{abstract}
Work is a necessity and routine for everyone. In doing ordinary work there are agencies where someone works. One of the workplaces is ConocoPhilips Suban. The existing work is to secure the goods in each wellies. Currently in the process of monitoring existing goods in the ConocoPililips Suban willes is still being done conventionally, especially the situation report for each wellies owned. For this reason, in this study the development of software used to monitor and manage the willes guarding schedule and find out the identity of anyone on duty in order to improve the performance of the members of guard. The software development used in this study is the waterfall model. Waterfall is a structured software development method with five stages namely communication, planning, modeling, construction and deployment. The results of the research are monitoring wellies software with three types of users, namely admin, patrol officer, guard officer. The software also has a menu in the form of data management officers, wellies, goods, and reports. The software has two types of display interfaces namely web-based used for admin type users and mobile interfaces used for officer type users. The results also showed that the software was able to monitor goods in each wellies so that the reporting carried out had good accuracy values.
\end{abstract}

Keywords: software, monitoring, waterfall, wellies, ConocoPhilips

\begin{abstract}
Abstrak: Pekerjaan merupakan kebutuhan dan rutinitas septiap orang. Dalam melakukan pekerjaan biasaya terdapat instansi tempat seseorang bekerja. Salah satu tempat kerja yang adalah ConocoPhilips Suban. Pekerjaan yang ada yaitu melakukan pengamanan barang yang ada pada setiap wellies. Saat ini dalam proses monitoring barang yang ada pada willes ConocoPhilips Suban masih dilakukan secara konvensional terutama laporan keadaan untuk setiap wellies yang dimiliki. Untuk itu di dalam penelitian ini dilakukan pengembangan perangkat lunak yang digunakan untuk monitoring dan mengatur jadwal penjagaan willes serta mengetahui identias siapa saja yang bertugas agar dapat meningkatkan kinerja para anggota penjagaan. Pengembangan perangkat lunak yang digunakan dalam penelitian ini adalah waterfall model. Waterfall merupakan metode pengembangan perangkat lunak yang terstruktur dengan lima tahapan yaitu komunikasi, perencanaan, pemodelan, konstruksi dan deployment. Hasi dari penelitian berupa perangkat lunak monitoring wellies dengan tiga jenis pengguna yaitu admin, petugas patroli, petugas jaga. Perangkat lunak juga memiliki menu berupa pengelolaan data petugas, wellies, barang, dan laporan. Perangkat lunak memiliki dua jenis tampilan antarmuka yaitu berbasis web yang digunakan untuk pengguna jenis admin dan antarmuka mobile yang digunakan untuk pengguna jenis petugas. Hasil penelitian juga menunjukkan bahwa perangkat lunak mampu untuk melakukan monitoring barang pada setiap wellies sehingga pelaporan yang dilakukan memiliki nila akurasi yang baik.
\end{abstract}

Kata kunci: perangkat lunak, monitoring, waterfall, wellies, ConocoPhilips

\section{PENDAHULUAN}

Perkembangan dunia digital pada era saat ini semua perangkat elektronika yang berbasiskan perangkat lunak mobile. Karena berperan menjembatani dan mengatur kinerja software aplikasi dengan hardware perangkat yang operasi, bicara tentang perangkat lunak mobile yaitu memiliki banyak jenis dalam hal ukuran, desain dan layout,tetapi mereka memiliki kesamaan karateristik yang sangat berbeda. Kali ini kami akan membangun sebuah system pada 
perusahaan ConocoPhilips yang berlokasi di Area Musi Banyuasin Suban Gas Plant.

ConocoPhilips merupakan salah satu perusahaan energi yang berskala internasional. Didalam Conocophilips, semua rata-rata aset negara yang di gunakan perusahaan tersebut baik di dalam bidang apapun sehingga apabila fasilitas tersebut mengalami kehilangan maka negara juga mengalami kerugian. Hal ini merupakan salah satu permasalahan yang sering dialami oleh pihak perusahaan di bidang jaga fasilitas wellis Conocophilips sering kali terjadi tindakan kriminal di karenakan banyak anggota petugas penjagaan fasilitas tidak hadir tepat waktu dan sering meninggalkan lokasi penjagaan bahkan sering menganggap remeh sesuatu yang ada di lingkungan kerja ConocoPhilips.

Dari uraian diatas maka dalam penelitian ini penulis akan melakukan pengembangan Perangkat Lunak Monitoring Wellies Dengan Metode Waterfall Model di lokasi Conocophilips Suban Area Musi Banyuasin, agar tidak terjadi dan mengurangi tindakan kriminal lalu kami memanfaatkan kemajuan zaman yang semakin berkembang dengan membangun sistem tersebut. Keuntungan dari sebuah sistem yang dibangun ialah fleksibel dalam hal bekerja walaupun dimanapun posisi keberadaan personil jaga, Meningkatkan keamanan para personil, meningkatkan efisiensi dan produktivitas personil, meningkatkan akurasi dan ketepatan data, meningkatkan proses bisnis yang sudah ada, dan meningkatkan customer satisfaction agar tidak mengalami kerugian akibat kehilangan aset yang ada di Area Wellis ConocoPhilips.
Namun juga terdapat kekurangan perangkat lunak berbasis mobile yaitu rendahnya jaringan bandwidth dan koneksi yang lemah sehingga membuat pengguna mobile sering terputus dari jaringan. Hal ini mungin terjadi karena beberapa alasan termasuk kegagalan sinyal, jangkauan sinyal kurang luas dapat membuat personil terlambat input data kehadiran, serta konsumsi tenaga yang berakibat pada perangkat lunak mobile sangat bergantung pada daya tahan baterai sehingga butuh daya charger arus listrik karena di area Wellis ConocoPhilips menggunakan tenaga pembangkit surya semua itu dapat diatasi dengan baik. Selain itu juga perangakt mobile dapat selalu dibawah oleh petugas ketika melakukan kontrol.

\section{METODOLOGI PENELITIAN}

Untuk menyelesaikan proses penelitian pengembangan Perangkat Lunak Monitoring Wellis maka terdapat metode yang digunakan yaitu sebagai berikut.

\subsection{Metode Penelitian}

Dalam melakukan peneltian pengembangan Perangkat Lunak Monitoring Wellis Dengan Metode Waterfall Model ini metode yang digunakan untuk menjelaskan hasil peneltian menggunakan teknik atau metode deskriptif. Dalam banya penelitian dijelaskan bahwa metode ini merupakan metode yang digunakan untuk menjelasakan fakta dan penomena sebuah objek yang diteliti berdasarkan pandangan peneliti. Dapat juga dikatakan bahwa metode penelitian dekkriptif merupakan paparan sebuah 
kedaan fakta yang diteliti berdasarkan perspektif peneliti [1].

\subsection{Metode Pengumpulan Data}

Adapun metode pengumpulan data yang digunakan dalam penelitian adalah sebagai berikut:

\subsubsection{Wawancara}

Dalam metode ini penulis mengumpulkan data penelitian dengan bertanya langsung kepada pihak terkait yang berkaitan dengan proses monitoring penjagaan welliis yang ada di area Wellis ConocoPhilips Suban.

\subsubsection{Observasi}

Metode ini dilakukan dengan cara mengamati langsung keadaan dan kegiatan pada objek guna mendapatkan keterangan yang akurat berkaitan dengan barang apasaja yang menjadi objek pnejaan pada area Wellis ConocoPhilips Suban.

\subsubsection{Dokumentasi}

Pengumpulan data dengan cara dokumentasi merupakan proses pengeumpulan data yang dilakukan denganc cara mengumpulkan dokumen baik dokumen pada objek maupun kajian pustaka berupa buku dan artikel jurnal yang berkaitan langsung dengan penelitian.

\subsection{Metode Pengembangan}

Untuk melakukan proess pengembangan perangkat lunak maka metode yang digunakan adalah metode waterfall. Metode waterfall merupakan salah satu metode yang terstruktur dari setiap langkah pengembangan yang dimiliki. Proses pegnemabangan dengan menggunakan waterfall model seperti yang diperlihatkan pada Gambar 1 [2].

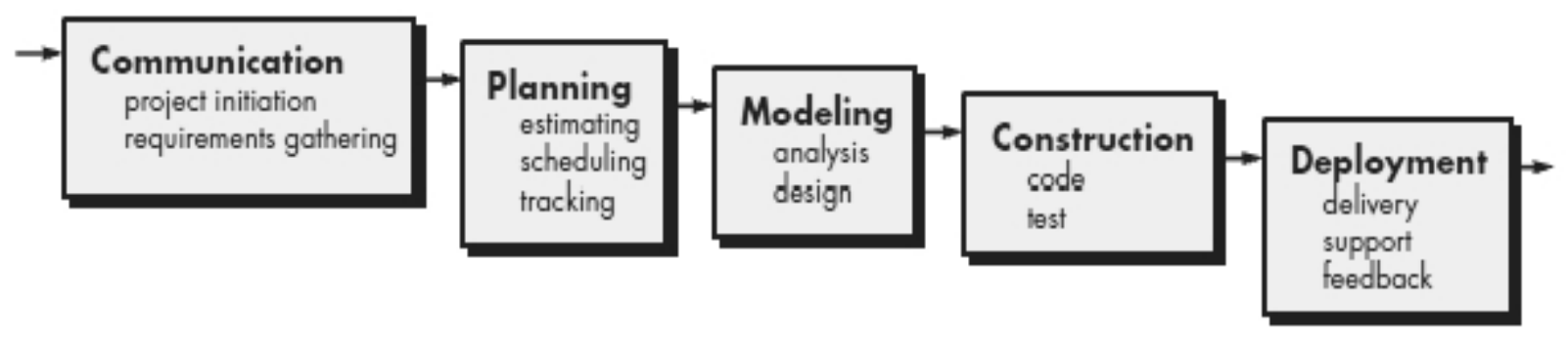

Gambar 1. Proses pengembangan waterfall

Dari Gambar 1 yang merupakan proses pegnembangan dengan menggunakan waterfall maka dapat dijelaskan masing-masing tahapan pengembangan tersebut sebagai berikut [3]:

\subsubsection{Communication}

Langkah ini merupakan analisis terhadap kebutuhan perangkat lunak, dan tahap untuk mengadakan pengumpulan data dengan melakukan pertemuan dengan objek penelitian, maupun mengumpulkan data-data tambahan baik yang ada di jurnal, artikel, maupun dari internet.

\subsubsection{Planning}

Proses planning merupakan lanjutan dari proses communication (analysis requirement). Tahapan ini akan menghasilkan dokumen perencanaan proses pengembangan perangkat 
lunak atau bisa dikatakan sebagai data yang berhubungan dengan proses pengerjaan.

\subsubsection{Modeling}

Proses modeling ini akan menerjemahkan syarat kebutuhan ke sebuah perancangan perangkat lunak yang dapat diperkirakan sebelum dilakukan pengkodean perangkat lunak. Proses ini berfokus pada rancangan struktur data, arsitektur perangkat lunak, representasi interface, dan detail (algoritma) prosedural.

\subsubsection{Construction}

Construction merupakan proses membuat coding atau pengkodean merupakan penerjemahan desain dalam bahasa yang bisa dikenali oleh komputer. Programmer akan menerjemahkan kebutuhan ke dalam bentuk antarmuka perangkat lunak melalui pengkodean. Tahapan inilah yang merupakan tahapan secara nyata dalam mengerjakan suatu perangkat lunak, artinya penggunaan komputer akan dimaksimalkan dalam tahapan ini. Setelah pengkodean selesai maka akan dilakukan pengujian terhadap sistem yang telah dibuat. Tujuan pengujian adalah menemukan kesalahankesalahan terhadap perangkat lunak untuk kemudian bisa diperbaiki.

\subsubsection{Deployment}

Tahapan ini bisa dikatakan final dalam pembuatan sebuah perangkat lunak. Setelah melakukan analisis, desain dan pengkodean maka sistem yang sudah jadi akan digunakan oleh user. Kemudian perangkat lunak yang telah dibuat harus dilakukan pemeliharaan secara berkala.

\section{HASIL DAN PEMBAHASAN}

Setelah melakukan proses penelitian sesuai dengan metodologi penelitian maka hasil penelitian berupa perangkat lunak monitoring wellies pada ConocoPhilips Suban. Untuk melihat bagaimana fungisonal perangkat lunak yang dihasilkan maka digambarkan dalam bentuk diagram unified modeling language (UML). Diagram UML merupakan diagram yang dapat digunakan untuk menggambarkan atau melihat bagaimana perangkat lunak secara keseluruhan dalam bentuk bluefrint perangkat lunak [4]. Dalam pengembangan perangkat lunak diagram yang digunakan yaitu use case diagram dan activity diagram.

Use case diagram digunakan untuk menggambarkan komponen atau interaksi antara pengguna dengan perangkat lunak [5]. Gambar 2 dapat dilihat merupakan use case diagram untuk perangkat lunak monitoring wellies ConocoPhilips Suban. Sesuai Gambar 2 dapat diketahui bahwa terdapat tiga jenis pengguna yaitu admin, petugas patroli dan petugas jaga wellies. Admin dapat melakukan pengelolaan data petugas, data wellies, data barang, laporan jaga, dan laporan wellies. Sedangkan petugas patroli dapat melakukan pengecekan petugas jaga dan petugas jaga dapat melakukan pengecekan barang yang ada pada wellies yang mereka jaga pada ConocoPhilips Suban. 


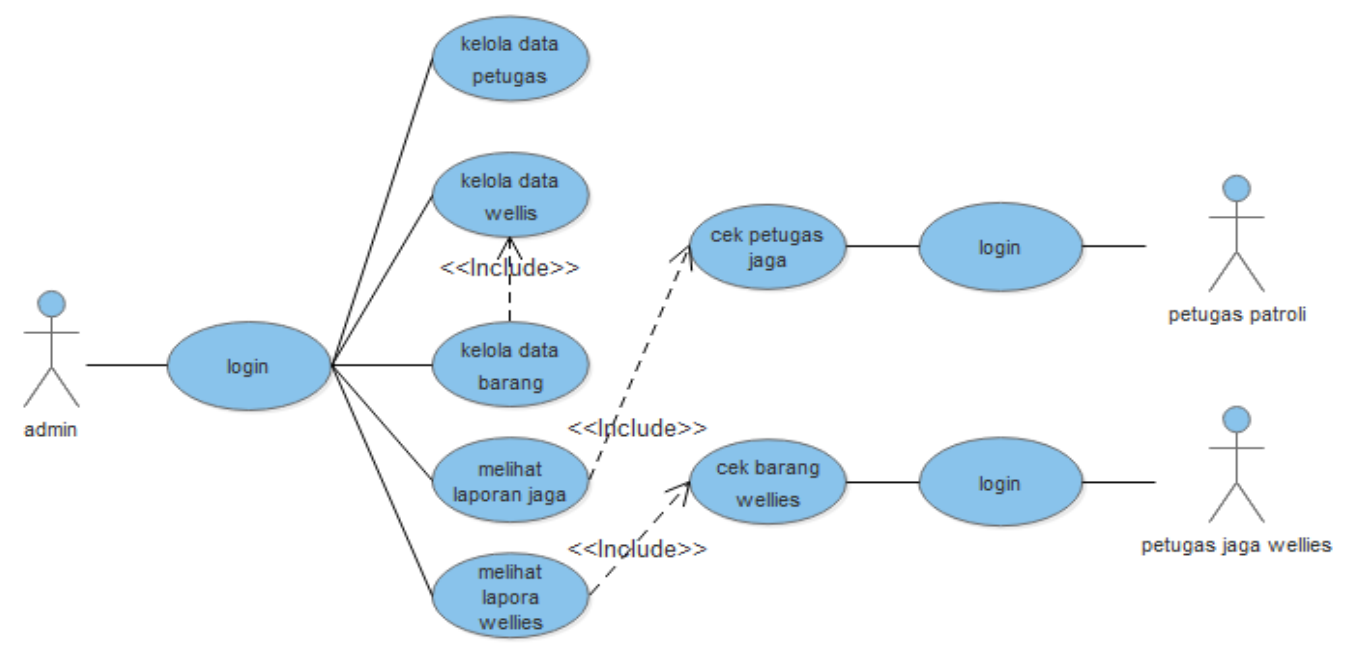

Gambar 2. Use Case Diagram

Selain dari use case diagram seperti yang diperlihatkan pada Gambar 2 maka digunakan juga activity diagram yang digunakan untuk menjelaskan bagaimana aktivitas pengguna ketika melakukan akses terhadap perangkat lunak monitoring wellies pada ConocoPhilips Suban seperti yang diperlihatkan pada Gambar 3 [6]. Seperti yang diperlihatkan pada Gambar 3 dapat diketahui bahwa untuk melakukan aktivitas pengelolaan data petugas, data wellies, data barang, laporan jaga, dan laporan wellies admin harus melakukan login dan begitu juga terjadi untuk pengguna dengan jenis yang lain yaitu petugas patroli dan petugas jaga.

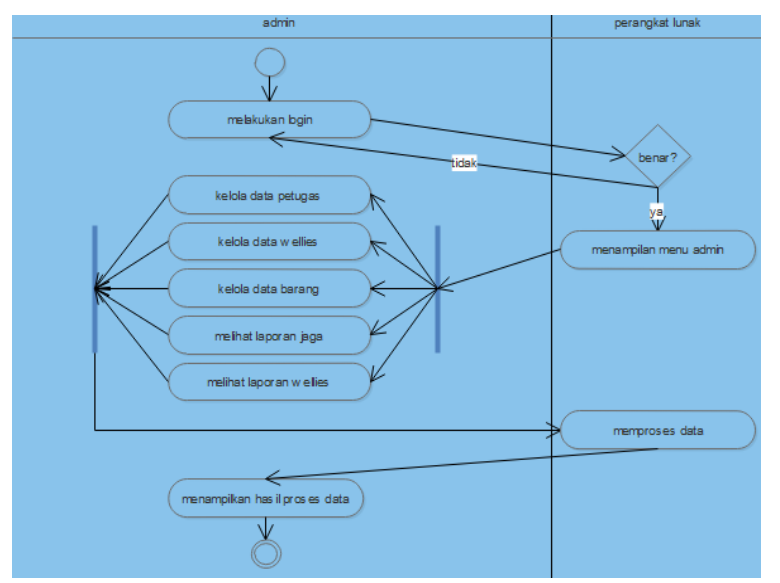

Gambar 3. Activity Diagram
Untuk melakukan aktivitas pada perangkat lunak monitoring wellies maka pengguna harus melakukan login seperti yang dijelaskan pada Gambar 3. Setelah melakukan login pengguna dapat melakukan aktivitas seperti yang diperlihatkan pada Gambar 4.

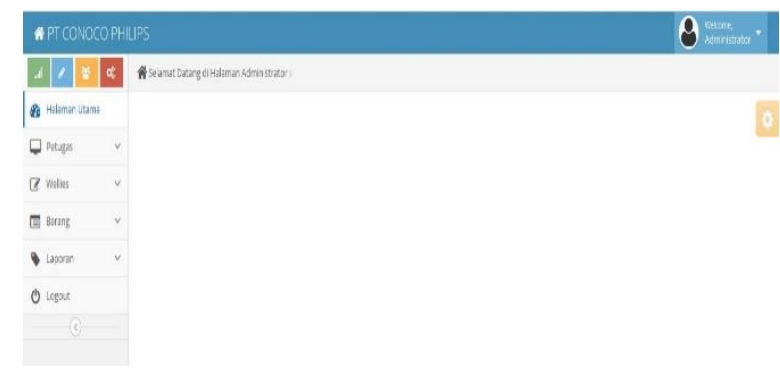

\section{Gambar 4. Halaman Utama Admin}

Gambar 4 merupakan tampilan halaman utama bagi admin untuk melakukan pengelolaan data yang tediri dari data petugas, data wellies, data barang, laporan jaga, dan laporan wellies. Menu petugas merupakan menu untuk melakukan pengelolaan data petugas. Ketika pertama kali diakses akan menampilkan form perugas. Form petugas dimana berfungsi sebagai menu input petugas yang terdiri dari nama petugas, telepon, asal daerah, tahun masuk dan kategori dimana disetiap form 
yang di input sesuai dengan nama form lalu simpan data. Dan data yang disimpan akan muncul kedalam admin data petugas. Form petugas sendiri seperti yang diperihatkan pada Gambar 5.

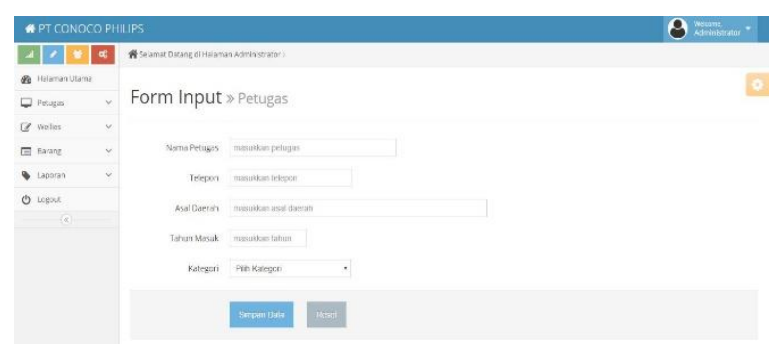

Gambar 5. Form Input Petugas

Selanjutnya adalah menu wellies merupakan menu untuk mengelolah data wellies. Seperti yang ditampilkan pada Gambar 6 dalam melakukan input data wellies data yang dimasukkan terdiri dari form nama wellis, lokasi, pengeboran, dan produksi.

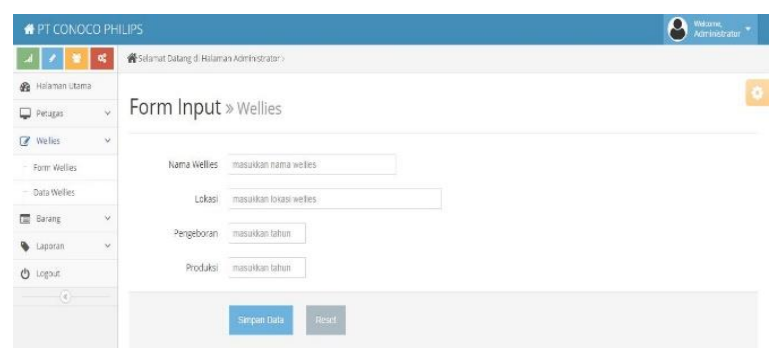

Gambar 6. Form Input Wellies

Setelah melakukan pengelolaan data wellies maka selanjutnya adalah melakukan pendataan barang yang ada pada setiap wellies. Data barang merupakan objek jaga yang dikontrol oleh petugas jaga dan diverifitasi oleh petugas patroli. Untuk melakukan input data barang maka dapat dilakukan seperti yang ditampilkan pada Gambar 7.

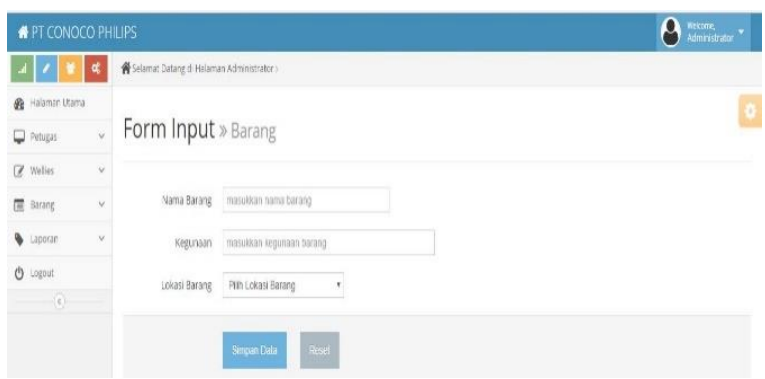

Gambar 7. Form Input Barang

Setelah melakukan input data barang maka admin dapat menampilkan data barang yang sudah ditambah dari form barang sesuai fasilitas yang ada dan dibutuhkan. Yang terdiri dari no, nama, kegunaan dan lokasi. Dari setiap data yang ada pada barang sangat penting bahkan tidak bisa di ganggu gugat karena apabila satu baris data barang hilang tanpa ada kejadian yang sesungguhnya maka barang di laporkan kepada pihak berwajib atau pihak perusahaan. Gambar 8 merupakan data barang yang ada untuk setiap wellies.

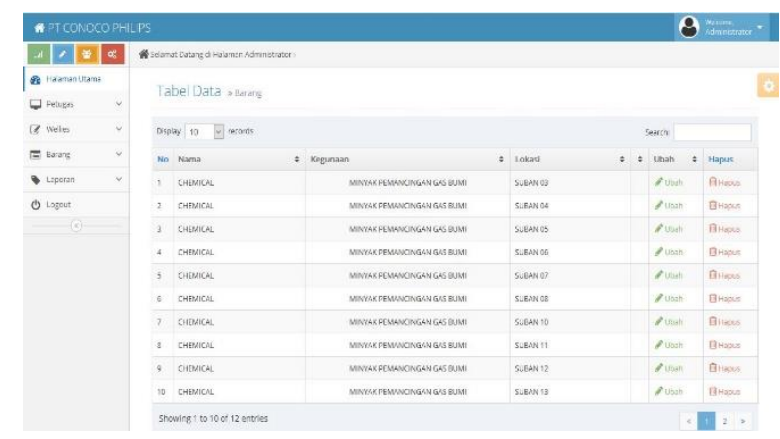

\section{Gambar 8. Data Barang Wellies}

Setelah semua proses semua dilakukan maka admin dapat melakukan pemantauan laporan monitoring wellies sesuai dengan data laporan yang diberikan oleh petugas jaga dan petugas patroli. Untuk melihat laporan maka admin dapat memilih wellies yang diinginkan, tahun dan bulan laporan seperti yang diperlihatkan pada Gambar 9. 


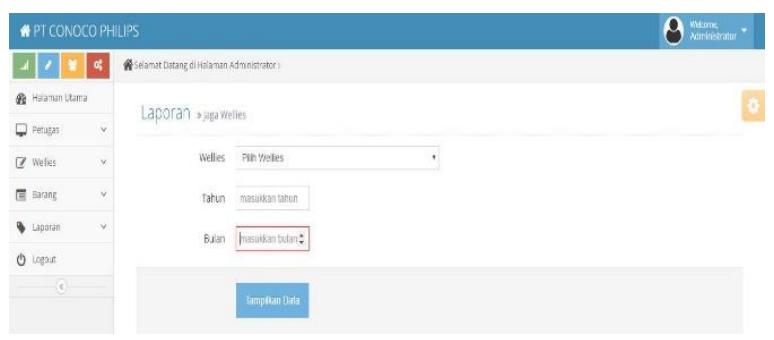

Gambar 9. Form Laporan Jaga Wellies

Proses yang tak kala pentingnya adalah proses pelaporan yang dilakukan oleh petugas patroli dan yang dijadikan laporan monitoring wellies. Untuk melakukan pelaporan monitoring barang pada wellies petugas diharuskan login terlebihdahulu sesuai dengan data petugas yang telah ditentukan ketika dimasukkan oleh admin perangkat lunak monitoring wellies ConocoPhilips Suban. Untuk melakukan aktivitas tersebut maka petugas harus melakukan login seperti yang diperlihatkan Gambar 10.

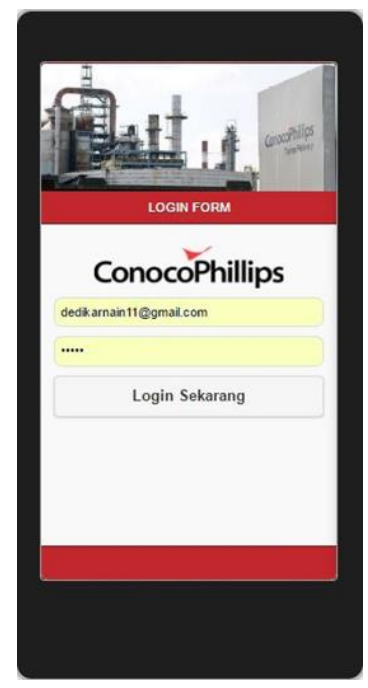

Gambar 10. Login Petugas

Ketika petugas sukses melakukan login seperti yang dilakukan pada Gambar 10 maka otomatis akan diarahkan ke halaman utama petugas seperti yang diperlihatkan pada Gambar 11 yang memiliki menu form hasil patroli, data patroli, ubah password dan keluar.

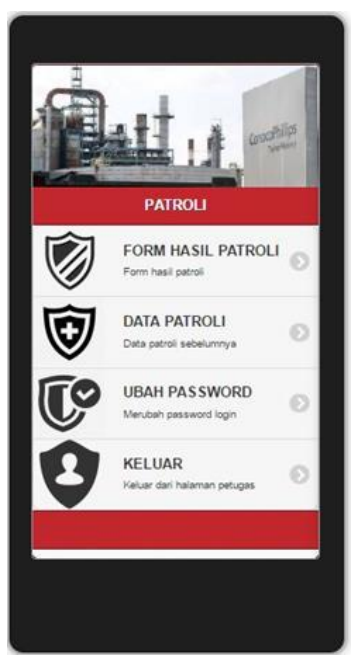

\section{Gambar 11. Menu Petugas}

Untuk melakukan pelaporan maka petugas dapat melakukan input data pada form hasil patroli dan akan ditampilkan form input seperti yang diperlihatkan pada Gambar 12 . Petugas dapat memilih nama wellies, status barang pada wellies dan keterangan laporan. Kemudian petugas dapat langsung mengirim data dan otomatis akan dapat dilihat oleh admin

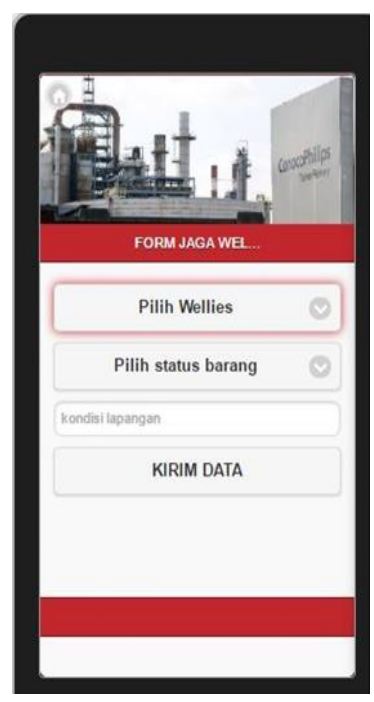

\section{Gambar 12. Form Pelaporan Wellies}

Data pelaporan yang telah dilakukan oleh petugas dapat dilihat pada menu data patroli. Data pelaporan tersebut tidak dapat diubah oleh petugas untuk memastikan integritas data. Data pelarporan terserbut seperti yang diperlihatkan pada Gambar 13. 


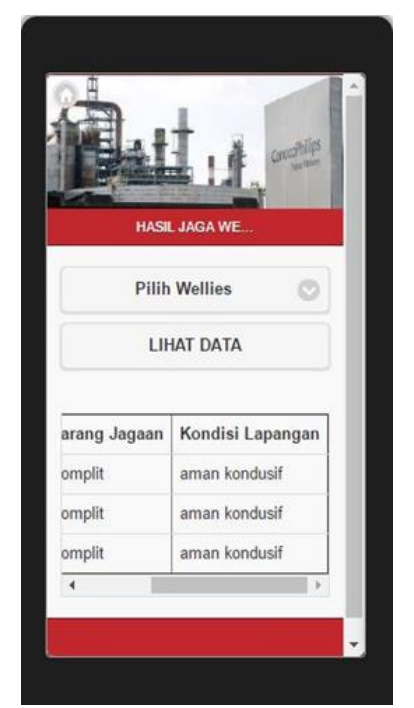

Gambar 13. Data Laoran Petugas

\section{KESIMPULAN}

Sesuai dengan proses penelitian dalam pengembangan perangkat lunak monitoring wellies pada ConocoPhilips Suban dapat disimpulkan beberapa hal yaitu:

1. Perangkat lunak monitoring wellies telah dikembangkan secara prosesdural menggunakan metode waterfall yang terdiri dari komunikasi, perencanaan, pemodelan, konstruksi, dan deployment.

2. Perangkat lunak monitoring wellies memiliki tiga hak akses pengguna yang terdiri dari admin, petugas jaga dan petugas patroli dengan aktivitasnya masing-masing.

3. Monitoring barang pada wellies dapat dilakukan dengan akurat sesuai dengan data patroli yang dilihat oleh petugas sehingga menjamin integritas data pelaporan.

\section{UCAPAN TERIMA KASIH}

Terima kasih diucapkan kepada semua pihak yang terlibat dalam penelitian ini terutama Universitas Bina Darma yang telah membiayai penelitian dan pihak ConocoPhilips yang bersesia memberikan informasi dan data berkaitan dengan penelitian yang dilakukan. Terima kasih juga disampaikan kepada pihak Jurnal MATRIK yang bersedia meluangkan waktu untuk melakukan review dan mempublikasi artikel ini.

\section{DAFTAR PUSTAKA}

[1] B. Tujni and F. Syakti, "IMPLEMENTASI SISTEM

USABILITY SCALE DALAM EVALUASI PERSPEKTIF PENGGUNA TERHADAP SISTEM INFORMASI AKADEMIK BERBASIS MOBILE," Ilk. J. Ilm., vol. 11, no. 3, pp. 241-251, 2019.

[2] F. Syakti, "Sistem Informasi Geografis Penderita Malaria pada Kelurahan Cereme Taba Kota Lubuklinggau," Digit. Zo. J. Teknol. Inf. dan Komun., vol. 10, no. 2, pp. 178-188, 2019.

[3] R. S. Pressman, "Software Engineering A Practitioner's Approach 7th Ed-Roger S. Pressman. Software Engineering A Practitioner's Approach 7th Ed-Roger S. Pressman." 2009.

[4] F. Purwaningtias and C. Mukmin, "PEMODELAN ENTERPRISE 
RESOURCE

PLANNING

MENGGUNAKAN ODOO PADA Z-

TECH KOMPUTER," KLIK-

KUMPULAN J. ILMU Komput., vol.

6, no. 3, pp. 275-283, 2019.

[5] N. Oktaviani and S. Sauda, "Pemodelan dan Implementasi Aplikasi Mobile Umrah Guide Menggunakan Unified Modeling Language," J. Sains dan Inform., vol. 5, no. 2, pp. 177-186, 2019.

[6] I. Effendy and A. M. Bakti, "INTEGRASI SMART ATTENDANCE BAGI DOSEN SEBAGAI UPAYA PENINGKATAN KINERJA," KLIK-KUMPULAN J. ILMU Komput., vol. 6, no. 3, pp. 317326, 2019. 